\title{
Implications of Different School Systems or Seasons on Tympanometry Results for School-age Children in Jordan
}

\author{
Original \\ Article \\ Wala' Sami Alaqrabawi', Jehad Ahmad Alaraifi', Hana Nawaf Mahmoud ${ }^{3}$, Sara \\ Wajdi Alhanbali, Zainab Mohammad Al Addasi ${ }^{5}$
}

Hearing and Speech Sciences Department, The University of Jordan

\begin{abstract}
Background and Objectives: This study aims at investigating different school systems (public schools, private schools, and United Nations Relief and Works Agency "UNRWA" schools) and whether different seasons can affect outer/middle ear function in school-age children in Jordan.

Patients and Methods: Otoscopic examination and tympanometry were performed to test outer and middle ear functions for 1578 children (938 boys, 640 girls) with a mean age of 8 years from different school systems; public schools, private schools, and UNRWA Schools. Children were either tested during autumn, winter, or spring. Differences in outer/middle ear function across children studying in different school systems and in different seasons were investigated.

Results: From a total of 1578 children, 429 (27\%) were found to have abnormal outer/middle ear function according to the tympanometry test results. The percentage of children with abnormal outer/middle function in public schools (38.1\%) was significantly higher than that in UNRWA (23.3\%) and private schools $(22 \%)$. The Percentages of children with abnormal outer/middle function in Spring (29.05\%) and in Autumn (28.87\%) were significantly higher than that in Winter $(19.07 \%) \mathrm{p}=0.001$.

Conclusion: The relatively high percentage of abnormal outer/middle ear function among school-age children in Jordan; specially in the public schools, might negatively impact their performance at school, if the cause is left untreated. Regular screening, including tympanometry for school-age children, is essential to ensure children continue their school life without sustaining disabilities caused by outer and middle ear disorders.
\end{abstract}

Key Words: Children, Jordan, middle ear pathology, seasonal disorder, tympanometry.

Received: 20 April 2020, Accepted: 23 April 2020

Corresponding Author: Wala' Sami Alaqrabawi, MSc, Audiology. Hearing and Speech Sciences Department, School of Rehabilitation Sciences, the University of Jordan Amman, Jordan (11942), Tel.: 9626536600, E-mail: w.aqrabawi@ju.edu.jo

ISSN: 2090-0740, July 2020 Vol.21, No.2

\section{INTRODUCTION}

Effective communication for school-age children is indispensable for an effective learning experience and enhanced skill acquisition. Presence of a hearing problem can negatively impact children's language, speech, academic and communication skill[ ${ }^{[1]}$. Conductive hearing loss is commonly noticeable across school-age children primarily due to otitis media and impacted wax ${ }^{[1,2,3,4]}$. Middle ear disorders such as otitis media might be linked to specific times and seasons. It is reported that otitis media is more prevalent in winter compared to other seasons of the year ${ }^{[5,6,7]}$. Otitis media might also be conveyed by a seasonal disease, such as upper respiratory infections ${ }^{[8]}$. Seasonal diseases usually occur during specific times of the year as a result of adopting specific habits (e.g., swimming) during specific months, or due to certain weather conditions ${ }^{[9]}$. Chonmaitree's study ${ }^{[10]}$ stated that otitis media occurred to more than $60 \%$ of young children who had a viral upper respiratory infection. Although considered a mild condition, otitis media with effusion decreases hearing acuity ${ }^{[11]}$.
A study conducted on Costa Rican Children suggested that otitis media was observed more in winter ${ }^{[12]}$. Another research study which collected and compared results of hearing screening tests on infants and school children in autumn, winter, and spring suggested a significantly low pass rate of school children in winter compared to spring and autumn. El-Sayed and Zakzouk, also reported that secretory otitis media was more prevalent in January and February compared to the rest of the year across children in Saudi Arabia ${ }^{[15]}$. A research study aimed at investigating the occurrence of otitis media and hearing loss among schoolage children in Canada (3-11 years) in April and October suggested that otitis media with effusion was the most common cause of middle ear problems. The percentage of middle ear problems was $24.4 \%$ in April compared to $25.5 \%$ in October ${ }^{[14]}$.

Geography is another factor that could affect hearing screening results in children ${ }^{[2,3,17,18]}$ and is associated with the state of economy and level of services provided at surveyed schools. According to the World Health Organization (WHO), hearing impairment is more 
prevalent across people living in low- and middle-income countries $^{[16]}$. Rural areas, for example, barely have private schools. Therefore, only basic services are provided to children at public schools and whose families tend to have a low income. People in rural areas are not adequately aware of the risk factors of otitis media, such as poor hygiene, allergies, and the exposure to smoke ${ }^{[17,18]}$. According to a study by Ologe (2003), chronic otitis media in rural public elementary schools was $6 \%$ in 699 children compared to $0 \%$ in 270 children in urban private elementary schools ${ }^{[3]}$. When it comes to effect of the economic status on the prevalence of otitis media, some studies reported that the lower the income, the higher the prevalence of otitis media $^{[11]}$.

In another study, the prevalence of otitis media in children attending a private school in Nepal was $5 \%{ }^{[2]}$. UNRWA Health Department Annual Report 2013 outlined hearing screening is conducted annually and children must pass a comprehensive medical examination as an admittance requirement ${ }^{[19]}$.

In view of findings of the discussed studies, it is hypothesized that tympanometry results will significantly differ between different school systems and seasons.

\section{Aims of the study:}

This study aims to: (i) compare prevalence of abnormal middle ear function across the four different seasons of the year, (ii) compare prevalence of abnormal middle ear function across children enrolled in different school systems including public (governmental) schools, private schools, and UNRWA schools (Palestine refugees schools in Jordan).

To the best of our knowledge, tympanometry results in school-age children were not studied to date in Jordan. Building public awareness about outer and middle ear disorders and their consequences on school-age children, and developing consensus standards for school-age children hearing screening, including outer and middle ear examination and management, are imperative in Jordan.

\section{METHODOLOGY:}

\section{Participants:}

A total of 1578 children were subjects of the study targeting children with a mean age of 8 years $(2.7$ SD; range 5 to 15 years). The sample included 475 children from public schools, 342 children from UNRWA schools, and 761 children from private schools across the city of Amman. 938 children of the sample are males and 640 are females.

Tests were conducted between November 2010 and May 2017 as part of school hearing screening. Screening were performed only three to four times during each school year due to some experienced difficulties in arrangements with schools. Children were tested during the first and second semesters; 329 children were tested in Autumn, 299 in Winter, and 950 in Spring.

Children with foreign body in the ear canal, recent ear surgery, active ear discharge, absent ear canal, or tenderness in the ear were excluded because tympanometry is contraindicated in such cases ${ }^{[20]}$.

\section{Procedures and Equipment:}

Two test procedures were performed; otoscopy and tympanometry according to the British Society of Audiology recommended procedures. Interacoustic MT10 portable tympanometer (Interacoustics, Assens, Denmark) was used with a probe tone of $226 \mathrm{~Hz}$. Results of tympanometry were analyzed in line with the British Society of Audiology recommended procedure for tympanometry $(2013)^{[20]}$. All tests were performed by certified audiologists and appropriate referrals were done following abnormal test findings. Consents were obtained from schools and the methodology was approved by the Institutional Ethics Committee. Results of tympanometry were considered abnormal, if there was either a flat tympanogram or a negative middle ear pressure (less than 150 da pa)

Type A tympanogram was indicative of a normal middle ear pressure and compliance. Type B tympanogram with a normal ear canal volume was considered to be abnormal and indicative of otitis media with effusion. Type B tympanogram with a low ear canal volume with a confirmed occluded wax seen in otoscopy was considered to be abnormal and indicative of impacted wax. Type B tympanogram with a high ear canal volume was considered to be abnormal and indicative of tympanic membrane perforation. Type $\mathrm{C}$ tympanogram with a retracted tympanic membrane was considered to be abnormal and indicative of a probable Eustachian tube dysfunction ${ }^{[21]}$.

\section{Analysis}

Data analysis was carried out using SPSS (version 18; SPSS Inc., Chicago, IL, USA) to investigate the effect of the independent variables; school systems and seasons on tympanometry findings, with a significant level at $(p<0.01)$. Either Chi-Square test or analysis of variance (ANOVA) was used to analyze the data.

\section{RESULTS}

Table 1 summarizes the findings of tympanometry in 1578 children. The percentage of children with abnormal tympanometry was $27 \%$ ( 429 children). It can be seen from (Table 1) that the percentage of abnormal tympanometry for females was $20.4 \%$ and $17.9 \%$ for males. Chi Square test results indicated that there was no significant difference found between males and females $(p=0.114)$. 
Table 1: Tympanometry findings.

\begin{tabular}{|c|c|c|c|c|c|}
\hline & \multicolumn{2}{|c|}{ Distribution of participants } & \multicolumn{2}{|c|}{ Abnormal tympanometry } & \multirow[b]{2}{*}{$p$-value } \\
\hline & $\mathrm{n}$ & $\%$ & Frequency & $\%$ & \\
\hline Total & 1578 & 100 & 429 & 27.19 & \\
\hline Gender & & & & & 0.114 \\
\hline Females & 640 & 40.6 & 196 & 12.42 & \\
\hline Males & 938 & 59.4 & 233 & 14.77 & \\
\hline \multicolumn{6}{|c|}{ School type } \\
\hline Public & 475 & 30.1 & 181 & 11.47 & $0.005^{1}$ \\
\hline UNRWA & 342 & 21.7 & 80 & 5.07 & $0.999^{2}$ \\
\hline Private & 761 & 48.2 & 168 & 10.65 & $<0.001^{3}$ \\
\hline \multicolumn{6}{|l|}{ Season } \\
\hline Autumn & 329 & 20.8 & 95 & 6.02 & $0.805^{4}$ \\
\hline Winter & 299 & 18.9 & 57 & 3.61 & $0.001^{5}$ \\
\hline Spring & 950 & 59.2 & 276 & 17.49 & $0.001^{6}$ \\
\hline
\end{tabular}

$1 P$-value for public and UNRWA schools. $2 P$-value for UNRWA and private schools. $3 P$-value for public and private schools. $4 P$-value $P$-value for autumn and spring. $5 P$-value for autumn and winter. $6 P$-value for spring and winter.

\section{System-Specific Effects}

Figure 1 shows an abnormal tympanometry percentage for each school type. Results of the ANOVA suggested that the percentage of participants with abnormal tympanometry results in public school (38.1\%) was significantly higher than the percentage of participants with abnormal tympanometry results in private schools $(p<0.001)$ and in UNRWA schools $(p=0.005)$. The abnormal tympanometry percentages were almost the same for both UNRWA (23.3\%) and private schools (22.0\%) and there was no significant difference found between them $(p=0.999)$.

Figure 1: Tympanometry findings for different school systems.

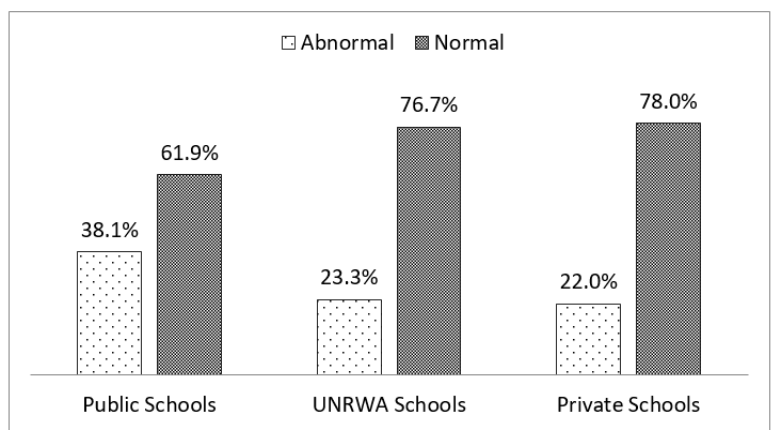

The effect of the school system on the tympanometry results was examined. (Figure 1) shows the abnormal tympanometry percentage for each school type. The percentage of abnormal tympanometry for public schools was $(38.1 \%)$ and it was significantly higher than that for both private $(p=0.000)$ and UNRWA $(p=0.005)$ schools. The abnormal tympanometry percentages were almost the same for both UNRWA (23.3\%) and private schools $(22.0 \%)$ and no significant difference was found between them $p=0.999$

\section{Seasonal Effects}

Figure 2 shows the abnormal tympanometry percentage for different seasons. Results of ANOVA suggested that the percentages of participants with abnormal tympanometry results were $(29.05 \%)$ in spring and $(28.87 \%)$ in autumn and were significantly higher than the percentage of participants with abnormal tympanometry results in winter $(19.07 \%) p=0.001$.

Figure 2: Season effect on tympanometry findings.

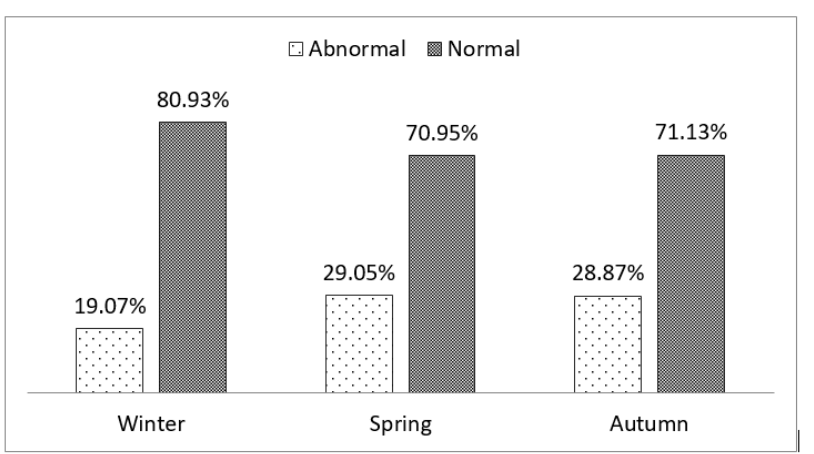

The effect of the different seasons on tympanometry findings was examined. (Figure 2) shows the abnormal tympanometry percentage for different seasons. It was revealed that the percentages of the abnormal tympanometry results in Spring $(29.05 \%)$ and Autumn (28.87\%) were significantly higher than that in Winter $(19.07 \%) p=0.001$. 


\section{Causes of Abnormal Tympanometry}

Figure 3 shows that the most common cause of abnormal tympanograms was impacted wax (9.54\%) followed by otitis media with effusion $(8.57 \%)$.

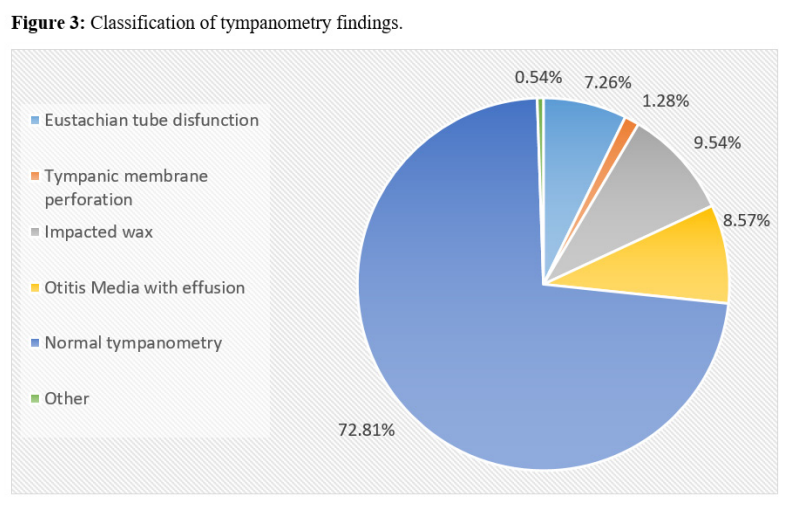

Fig. 3: Shows that the commonest causes of abnormal tympanograms were found to be impacted ear wax followed by otitis media with effusion.

\section{DISCUSSION}

This study showed that some preventable and treatable ear diseases, such as impacted wax and otitis media with effusion, pose significant health problems to school-age children in Jordan, often causing hearing loss and ear pain, thus, impeding children's academic learning and language acquisition. Therefore, it is critical to have a proper referral system in place to provide early and proper intervention.

In the present study, it was observed that abnormal tympanometry is affected by different school systems. Prevalence of abnormal tympanometry in public schools was significantly higher than that in both UNRWA and private schools. This is consistent with the findings of a study in Nigeria that reported a higher prevalence of chronic otitis media in rural public elementary schools than that in the urban private elementary schools ${ }^{[3]}$. These findings may be attributed to access to better health services, personal hygiene, socioeconomic status, and adequate health awareness within private and UNRWA schools, which could obviously affect the percentage of middle ear disorders $[2,3,17,18]$.

The increased prevalence of otitis media could be attributed to a number of reasons in public schools compared to private schools. First of all, the increasing number of students in private schools' classrooms might suggest increased chance of the spread of infections considering how crowded these classrooms have become. Classrooms in public schools are also not regularly heated during the colder months, increasing chance of colds in children. Notably, students in public schools tend to have more siblings compared with children in private schools, increasing chances of infection transmission through siblings. Another reason might be the availability of student clinics in private schools but not in public schools. Therefore, students in private schools might be privileged to get regular medical checks compared to students in public schools. One final reason might be the considerably high annual tuition fees levied by private schools. Children in public schools, however, tend to come from families with low socioeconomic status, and are usually known to have more health issues.

This study found that ear diseases are most common in spring and autumn than in winter, contrary to a previous study which traced middle ear pathology among school-age children in cold weather in Canada and in moderate weather in Jordan, and reported that percentage of middle ear pathology was higher in winter $^{[14]}$. Studies carried out in many countries like Costa Rica, Iraq, and Saudi Arabia indicated that different ear diseases, such as otitis media, are most common in winter compared to autumn and spring ${ }^{[5,6,7}$, $12,13,15]$. The climate of Jordan is overall dry and moderate compared to the hot and humid climate of these countries. Jordan's environment has significant aeroallergen seasons that may exacerbate allergic rhinitis. Moreover, in Jordan, pollen dispersal is concentrated in spring and autumn ${ }^{[22]}$. Pollen allergy can ultimately trigger ear diseases, and the prevalence of these allergic diseases is estimated to range from $15 \%$ to $20 \%$ in Jordan ${ }^{[23]}$. Moreover, it was reported that respiratory tract disease epidemics, which are associated with middle ear disorders, began in winter, and increased during spring in Jordan ${ }^{[24]}$.

This study indicated that the impacted wax is the most common ear problem among children in Jordan with a prevalence of $9.54 \%$. This is similar to the prevalence of impacted wax reported in the United State of America $(10 \%)^{[25]}$. However, prevalence of impacted wax observed in the present study may be an underestimation, as the age range of children included in this study is higher than that in the American children study, despite the similar examination method. Studies carried out at developing countries like Egypt, Malaysia, and Nigeria ${ }^{[26,27,28,4]}$ documented that prevalence of impacted wax ranges from $7.4 \%$ to $63 \%$.

The study targeted one of the main issues related to ear disorders, which is time or season of the year. It would be interesting if the same children are studied over two periods (one in spring and another in winter) and cover a larger number of children from different cities in Jordan as well. 


\section{CONCLUSION}

It is very important to perform ear examination and hearing screening at schools throughout the year, especially in spring and autumn.

Additionally, UNRWA, public or private school systems should ensure medical or habilitation professionals (e.g., audiologists or trained nurses) are hired to conduct hearing screening and ear examination annually, provide better healthcare services, and raise awareness that could enhance the educational experience, language acquisition and social development of school children.

\section{CONFLICT OF INTEREST}

There are no conflicts of interest.

\section{REFERENCES}

1. Daud MKM, Noor RM, Rahman NA, Sidek DS, Mohamad A. The effect of mild hearing loss on academic performance in primary school children. International Journal of Pediatric Otorhinolaryngology 2010;74:67-70.

2. Adhikari P, Joshi S, Baral D, Kharel B. Chronic suppurative otitis media in urban private school children of Nepal. Brazilian Journal of Otorhinolaryngology 2009;75:669-672.

3. Ologe FE, Nwawolo CC. Chronic suppurative otitis media in school pupils in Nigeria. East African Medical Journal 2003;80:12-16

4. Olusanya BO, Okolo AA, Adeosun AA. Predictors of hearing loss in school entrants in a developing country. Journal of Postgraduate Medicine 2004;50:173-179.

5. Cheong KH, Hussain SSM. Management of recurrent acute otitis media in children: systematic review of the effect of different interventions on otitis media recurrence, recurrence frequency and total recurrence time. The Journal of Laryngology and Otology 2012;126:874-885.

6. Aloqaili R, Ameen MK, Dhuha SN, Almusawi IHN. Bacterial etiology of acute otitis media in Baghdad. World Journal of Pharmacy and Pharmaceutical Sciences 2010;4:266-275.

7. Howard D. Intercultural Communications and Conductive Hearing Loss. First Peoples Child \& Family Review 2007;3:96-105.
8. Eccles R. An explanation for the seasonality of acute upper respiratory tract viral infections. Acta Otolaryngol 2002;122:183-191.

9. Mourtzoukou EG, Falagas ME. Exposure to cold and respiratory tract infections. The International Journal of Tuberculosis and Lung Disease 2007;11:938-943.

10. Chonmaitree T, Revai K, Grady JJ, Clos A, Patel JA, Nair S, et al. Viral upper respiratory tract infection and otitis media complication in young children. Clin Infect Dis. 2008;46:815-23.

11. Siddartha, Bhat V, Bhandary SK, Shenoy V, Rashmi. Otitis media with effusion in relation to socio economic status: A community-based study. Indian J Otolaryngol Head Neck Surg 2012;64:56-58.

12. Guevara S, Soley C, Arguedas A, Porat N, Dagan R. Seasonal distribution of otitis media pathogens among Costa Rican children. The Pediatric Infectious Disease Journal 2008;27:12-16.

13. Kei J, Robertson K, Driscoll C, Smyth V, McPherson $\mathrm{B}$, Latham $\mathrm{S}$, et al. Seasonal effects on transient evoked otoacoustic emission screening outcomes in infants versus 6-year-old children. Journal of the American Academy of Audiology 2002;13:392-399.

14. Langan LA, Sockalingam R, Caissie R, Corsten G. Occurrence of otitis media and hearing loss among First Nations Elementary School children. Journal of Speech-Language Pathology and Audiology 2007;31:178-185.

15. El-Sayed Y, Zakzouk S. Point prevalence of type B tympanogram in Riyadh. International Journal of Pediatric Otorhinolaryngology 1995;31:53-61.

16. World Health Organization (WHO). Fact Sheets: Deafness and hearing loss. 2015, [cited in 2018 November 1]Available from URL:http://www.who. int/mediacentre/factsheets/fs300/en/.

17. Shrikrishna BH, Jyothi A. Awareness Regarding Otitis Media in Patients Belonging to Rural Population of Raichur District, Karnataka. International Journal of Research in Pharmaceutical and Biomedical Sciences 2013;4:1233-1238.

18. BowdAD. Otitis media: health and social consequences for aboriginal youth in Canada's north. International Journal of Circumpolar Health 2005;64:5-15.

19. UNRWA. Department of Health Annual Report: Medical Screening 2013, [cited in 2018 November 
15]. Available from URL:http://www.unrwa.org/sites/ default/files/health_annual_report_2013.pdf.

20. British Society of Audiology (BSA) Recommended Procedure for Tympanometry. 2013, [cited in 2018 October 1]. Available from URL:https:// www.thebsa.org.uk/wp-content/uploads/2013/04/ Tympanometry-1.pdf.

21. Jerger, J. Clinical experience with impedance audiometry. Archives of Otolaryngology - Head and Neck Surgery 1970; 92:311-324.

22. Al-Eisawi D, Dajani B. Airborne pollen of Jordan. Grana 1988;27:219-227.

23. Aburuz S, Bulatova N, Tawalbeh M. Skin prick test reactivity to aeroallergens in Jordanian allergic rhinitis patients. Eastern Mediterranean Health Journal 2011;17:604-610.
24. Bdour S. Respiratory syncytial virus subgroup A in hospitalized children in Zarqa, Jordan. Annals of tropical paediatrics 2001; 21:253-261.

25. Bricco E. Impacted cerumen as a reason for failure in hearing conservation programs. J. Sch. Health $1985 ; 55: 240-241$.

26. Mourad MI, Farghaly NF, Mohammed HG. Hearing impairment: Is it a public health problem among school pupils in Alexandria. J Egypt Public Health Assoc 1993;68:703-726.

27. Lyn C, Jadusingh WA, Ashman H, Chen D, Abramson A, Soutar I. Hearing screening in Jamaica: Prevalence of otitis media with effusion. Laryngoscope 1998; 108:288-290.

28. Elango S, Purohit GN, Hashim M, Hilmi R, Hearing loss and ear disorders in Malaysian school children. Int.J. Pediatr. Otorhinolaryngol 1991; 22:75-80. 